\title{
A ausência de Jesús Martín-Barbero nos estudos de comunicação em Portugal ${ }^{1}$ The absence of Jesús Martín-Barbero in the Communication Studies in Portugal
}

\author{
ISABEL FERIN CUNHAa \\ Universidade de Coimbra, Faculdade de Letras, Centro de Investigação. Coimbra, Portugal \\ FERNANDA CASTILHOb \\ Centro Estadual de Educação Tecnológica Paula Souza, Faculdade de Tecnologia. São Paulo - SP, \\ Brasil \\ Universidade de São Paulo, Escola de Comunicações e Artes. São Paulo - SP, Brasil
}

\begin{abstract}
RESUMO
O objetivo desse trabalho é discutir a ausência de Jesús Martín-Barbero nos estudos de ciências da comunicação em Portugal. Tendo em conta que os fluxos acadêmicos entre Brasil e Portugal são intensos, teríamos como hipótese o compartilhamento de bibliografia e metodologias a partir da introdução de autores brasileiros e latino-americanos em Portugal e de portugueses no Brasil. No entanto, esta partilha é esporádica nos dois lados do Atlântico, e nela não se inclui Martín-Barbero de forma sistemática. Objetivamos, por esta razão, mapear sua presença, nomeadamente nos estudos sobre recepção e cultura, e identificar as razões que a levam a ser tão discreta no contexto da pesquisa portuguesa. Palavras-chave: Jesús Martín-Barbero, espaço lusófono, fluxos acadêmicos, anglo-internacionalização
\end{abstract}

\section{ABSTRACT}

The objective of this work is to discuss the absence of Jesús Martín-Barbero in studies on communication sciences in Portugal. Considering that academic flows between Brazil and Portugal are intense, we would have as hypothesis the sharing of bibliography and methodologies from the introduction of Brazilian and Latin American authors in Portugal and of Portuguese authors in Brazil. However, this sharing is sporadic on both sides of the Atlantic, and it does not include Martín-Barbero systematically. Therefore, we aim to trace his presence, especially in reception and culture studies, and the determine the reasons that lead to such little presence in the context of Portuguese research.

Keywords: Jesús Martín-Barbero, Lusophone space, academic flows, anglo-internationalization a Professora associada da Universidade de Coimbra. Foi vice-presidente do Centro de Investigação Media e Jornalismo (2004-2006) e coordena projetos aprovados pela Fundação Ciência e Tecnologia de Portugal. Orcid: https://orcid.org/0000 -0001-8701-527X. E-mail: barone.ferin@gmail.com

${ }^{\mathrm{b}}$ Professora da Faculdade de Tecnologia do Centro Paula Souza. Pós-doutora pela Universidade de São Paulo (USP), mestre e doutora pela Universidade de Coimbra e pesquisadora do Centro de Estudos de Telenovela da Universidade de São Paulo. Orcid: https://orcid.org/0000 -0003-2301-0554. E-mail: fernanda.castilho7@usp.br 


\section{INTRODUÇÃO}

TESÚS MARTÍN-BARBERO, nascido em Espanha, refez simbolicamente o percurso d'A jangada de pedra de Saramago (1986) ao se estabelecer como pesquisador na Colômbia. Navegou pelos mares do Atlântico vindo colidir com as Américas, tornando-se referência teórica na tradição latino-americana de estudos de comunicação. A principal questão de pesquisa deste artigo consiste em observar o inverso: discutir a presença/ausência e o possível impacto (ou não impacto) do pensamento de Martín-Barbero no campo dos estudos de ciências da comunicação em Portugal.

A inspiração fundamental para essa investigação partiu da hipótese que os fluxos acadêmicos entre Brasil e Portugal possibilitariam o compartilhamento de bibliografias e metodologias comuns, sobretudo no âmbito dos estudos comparados do sistema midiático lusófono (Cunha, 2017a). Neste sentido, a influência latino-americana se encontra presente desde o início da década de 1990, especialmente por intermédio das pesquisas brasileiras, fundamentando-se em autores como Martín-Barbero, Nora Mazzioti e Guillermo Orozco Gómez (Cunha, 2010).

Em 2017, a obra de referência de Martín-Barbero, De los medios a las mediaciones: comunicación, cultura e hegemonía, completou 30 anos de publi-

${ }^{1}$ A primeira edição foi publicada em 1987, pela editora Gustavo Gili (Barcelona/Cidade do México). cação ${ }^{1}$. Nesse livro, o autor aponta como principal objetivo investigar o processo comunicativo a partir das mediações e dos sujeitos, ou seja, a partir das articulações entre as práticas de comunicação e os movimentos culturais. Ao propor o entendimento da comunicação a partir da cultura, a obra de Jesus Martín-Barbero influenciou grande parte dos estudos do campo das ciências da comunicação no Brasil. No entanto, notamos que o mesmo não ocorreu em Portugal, onde se observa uma influência inicial, nas décadas de 1970 e 1980, da semiótica de origem francesa, e a partir da década de 1990, dos estudos de mídia e comunicação de matriz anglo-saxônica.

Um simples folhear dos resumos e textos publicados em atas de congressos, conferências ou seminários, que congregam docentes e pesquisadores da lusofonia e da Ibero-América, permite notar que a presença de autores desta última proveniência não tem lugar nas publicações científicas portuguesas, sendo o contrário igualmente observável.

Indo mais a fundo, elaboramos um conjunto de questões para consultar, por meio de entrevistas, os investigadores da área que tiveram envolvimento com a obra de Martín-Barbero ou que representam importantes nomes da pesquisa em Portugal, formando uma pequena amostra qualitativa por conveniência. A solicitação foi enviada a dez pesquisadores e obtivemos seis respostas (duas indicaram pouco conhecimento da obra para discorrer a respeito), e quatro delas 
foram convergentes no sentido de apontar a real ausência de Martín-Barbero nas pesquisas portuguesas em ciências da comunicação.

Num segundo momento, foi realizado um levantamento sistemático dos artigos que citaram Martín-Barbero pelo menos uma vez, por meio da consulta aos anais/atas de congressos organizados por associações científicas dos países lusófonos ou ibero-americanos (Ibercom, Confibercom, Lusocom e Sopcom). Foram observados todos os documentos atualmente disponíveis em formato digital nos sites oficiais dessas associações. Tal recorte originou uma amostra de dezoito anais/atas publicados entre os anos 2000 e 2015, conforme a periodicidade de cada evento. Além disso, reunimos todos os Anuários Internacionais da Comunicação Lusófona entre 2007 e 2016. Ao todo, foram consultadas 27 publicações ${ }^{2}$, cujos resultados reforçam o conteúdo das entrevistas.

Questionamos por essa razão as causas que levam ao desconhecimento mútuo, tendo em conta a existência de uma língua de raiz partilhada, como o português e o castelhano; contatos frequentes e periódicos, a partir de eventos científicos consolidados, e acesso à produção mútua, por meio de bibliotecas on-line.

Com estas constatações presentes, o objetivo deste trabalho é produzir uma reflexão teórica, com base em dados empíricos exploratórios, sobre esta problemática tendo como foco a presença, ou ausência, do pensamento do maior teórico da comunicação latino-americano, Jesús Martín-Barbero, no campo dos estudos de ciências da comunicação em Portugal. Associada a este propósito, pretende-se identificar o papel os fluxos acadêmicos entre Brasil e Portugal, na divulgação científica do trabalho deste investigador e perceber a contribuição científica que lhe é atribuída nos estudos sobre mídia e comunicação em Portugal.

\section{OS ESTUDOS DE COMUNICAÇÃO EM PORTUGAL: UM CAMPO DE LUTAS}

Os estudos de comunicação em Portugal possuem uma trajetória bastante particular frente ao percurso de outros países historicamente e/ou culturalmente próximos, como Espanha e Brasil. Embora esses países também tenham sofrido regimes ditatoriais, a principal característica que diferencia Portugal desses contextos diz respeito ao início extremamente tardio das escolas de comunicação, em virtude da desconfiança face a esta área durante o regime salazarista (Ribeiro, 2016).

É importante notar que as ditaduras nos países ibéricos limitaram a liberdade de expressão não apenas ao reprimir e censurar conteúdos, mas também ao deter o controle de propriedade dos meios. No entanto, enquanto na Espanha o
${ }^{2}$ Os 27 documentos somam 29.541 páginas e cerca de $2 \mathrm{mil}$ artigos: Ibercom (3 atas/3 anos); Confibercom (1 ata/ano); Lusocom ( 9 anuários); Lusocom (5 atas/3 anos) e Sopcom (9 atas/3 anos). 


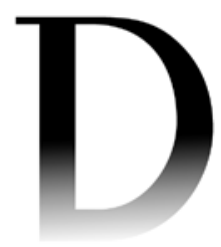

${ }^{3}$ Paulo Serra (2017) observa os percursos de Adriano Duarte Rodrigues, Universidade Nova de Lisboa; Aníbal Augusto Alves, Universidade do Minho; José Paquete de Oliveira, Instituto Superior de Ciências do Trabalho e da Empresa, Instituto Universitário de Lisboa; Moisés de Lemos Martins, Universidade do Minho; António Carreto Fidalgo, Universidade da Beira Interior. a ditadura portuguesa nunca apoiou o ensino do jornalismo ou outras áreas de comunicação no ensino técnico e superior (Ibid.). Apesar de a ditadura nunca apoiar um curso de jornalismo no ensino universitário, a verdade é que esta formação esteve presente desde 1963 nos Estudos Ultramarinos do Instituto Superior de Ciências Sociais e Políticas Ultramarinas, curso que preparava os quadros superiores da administração colonial. Os estudos foram iniciados como uma disciplina de sociologia da informação (Gonçalves, 1963) e posteriormente como curso de jornalismo (Rego et al., 1963). A primeira Escola Superior de Meios de Comunicação Social, de fundos privados, foi criada apenas em 1971, em Lisboa, tendo sido encerrada após a Revolução dos Cravos, em 1974, com a consequente nacionalização do banco que a financiava (Ribeiro, 2016). O primeiro curso de comunicação social surge efetivamente na Faculdade de Ciências Sociais e Humanas da Universidade Nova de Lisboa, em 1979 (Mesquita; Ponte, 1997).

Outro fator de interesse se refere à histórica ligação entre ensino e Igreja católica na Península Ibérica que, em certa medida, também se verifica quando observamos o início do ensino de comunicação no país. Como nota Paulo Serra, os professores "fundadores"3 dos cursos na área, entre os quais estão Adriano Duarte Rodrigues (Universidade Nova de Lisboa) e Moisés de Lemos Martins (Universidade do Minho), possuem um percurso católico atrelado às suas histórias de vida: "todos eles tiveram uma ligação mais ou menos estreita à Igreja católica, havendo 2 ex-sacerdotes, 1 ex-frade, e 2 ex-seminaristas/estudantes de teologia" (2017: 134). Esta genealogia não se faz sentir apenas na fundação moderna das ciências da comunicação, mas advém do interesse da Igreja católica em divulgar a sua mensagem religiosa, notando-se essa presença desde o início da Expansão ultramarina, a partir das traduções e simplificações de textos religiosos direccionados aos povos do além-mar (Cunha, 2017a: 18-22). Se considerarmos ainda o período da ditadura, podemos constatar que abundam órgãos de comunicação que são propriedade da Igreja católica, bem como eclesiásticos com grande poder na gestão da informação pública (Rego et al., 1963). Sublinhamos que na refundação das ciências da comunicação em Portugal a partir da década de 1970, o corpo docente mobilizado advém prioritariamente de áreas de formação como a filosofia, a linguística e a história, em que a influência da academia francesa se fez sentir até meados dos anos 1980. A chegada do professor Nelson Traquina, de origem portuguesa e educado nos Estados Unidos, à Universidade Nova de Lisboa nos anos 1980, faz com que o paradigma nos estudos da comunicação e do jornalismo se direcione para as escolas anglo-saxônicas, norte-americana e inglesa (Cunha; Cabrera; Sousa, 2012). 
De forma sistemática, a trajetória da mídia em Portugal pode ser dividida em períodos constituídos por marcos históricos, políticos e sociais bastante definidos, conforme propõe a seguinte periodização:

$1^{\circ}$ período, vigência do Estado Novo (apesar das características muito peculiares de determinados períodos), caracterizando-se pela relação estabelecida entre comunicação, propaganda e conteúdos, expansão da imprensa diária e periódica, implantação da rádio e da televisão (1935-1974); $2^{\circ}$ período, compreende a Revolução do 25 de abril e as acções da nacionalização e intervenção do Estado no campo dos media (1974-1976); $3^{\circ}$ período compreende os anos de Normalização Democrática (Maxwell, 1999) que abrangem os anos de 1977 a 1989; $4^{\circ}$ período, entre os anos de 1990 e 1999, corresponde num primeiro momento à rearticulação do campo dos media em torno dos operadores privados de televisão e, num segundo momento, às lutas de audiência entre estes e o grupo do Estado. $\mathrm{O} 5^{\circ} \mathrm{e}$ último período, de 2000 a 2005, abarca uma fase pautada pela contração do mercado, racionalização de recursos e apostas em novos produtos. (Cunha, 2011: 13-14)

Percebemos assim, conforme mencionado, que os fluxos de informação foram cerceados até meados da década de 1970, culminando no surgimento igualmente tardio dos estudos em comunicação. Por essa razão, a área é considerada ainda recente em Portugal (Ribeiro, 2016).

É nesse sentido que observamos que a luta pelo reconhecimento e pela afirmação desse campo científico (Bourdieu, 1983) é uma realidade, visto que, por um lado, a própria história dos estudos de comunicação é um tópico debatido por poucos autores portugueses (Ribeiro, 2016). Por outro lado, a dificuldade em encontrar espaços autônomos nas universidades portuguesas é um entrave que fragiliza o campo, sobretudo em termos de busca por financiamento. Exemplos das lutas simbólicas nos espaços estruturados das faculdades, onde, nos termos de Bourdieu (1983), há dominantes e dominados, podem ser encontrados ao observar a posição dos estudos de comunicação nas universidades. Normalmente, os departamentos de comunicação estão integrados às faculdades de ciências sociais e humanas, caso da Universidade Nova de Lisboa. Em Coimbra, exemplo emblemático, como também aponta Nelson Ribeiro (2016), a comunicação encontra-se atualmente como uma seção do Departamento de Filosofia, Comunicação e Informação, componente da vasta Faculdade de Letras ${ }^{4}$.

Como refere Serra (2017: 134), também no sentido bourdiano, a iniciativa de construção do campo da comunicação envolve resistência frente aos campos estabelecidos e consolidados, nomeadamente por se tratar de uma
${ }^{4}$ Ao todo, a Faculdade de Letras da Universidade de Coimbra (FLUC) possui quatro grandes departamentos, com cursos de diversas áreas, de arqueologia a história. 
área aglutinadora de saberes, com grande trans e interdisciplinaridade, sendo por isso frequentemente identificada por outras áreas pela suposta ausência de especificidade ou pureza científica.

\section{ESTUDOS DE COMUNICAÇÃO NA IBERO-AMÉRICA: O PAPEL DAS ASSOCIAÇÕES CIENTÍFICAS}

Considerando suas propostas, a constituição das associações científicas pode ser observada como importante estratégia de fortalecimento do campo das ciências da comunicação no espaço lusófono e ibero-americano. Podem representar um progresso em termos de internacionalização/reafirmação do conhecimento local (Romancini, 2017), promover o debate e potenciar o maior conhecimento entre comunidades de investigadores (Marcos; Moreno, 2003; Melo, 2009). Para o propósito deste artigo (que problematiza a ausência, em Portugal, da obra de um importante autor latino-americano), interessa mencionar as finalidades das seguintes organizações: Sopcom (Associação Portuguesa de Ciências da Comunicação), Lusocom (Federação Lusófona de Ciências da Comunicação), Assibercom (Associação Ibero-americana de Comunicação) e Confibercom (Confederação Ibero-Americana das Associações Científicas e Acadêmicas de Comunicação). Comparativamente, todas possuem objetivos semelhantes, conforme os campos de ação geográfica de sua competência, pretendendo, por exemplo:

- Promover a investigação nos domínios das ciências da comunicação (Sopcom);

- Fomentar o desenvolvimento de pesquisas transnacionais sobre a comunicação (Assibercom);

- Elaborar e/ou promover projetos de investigação transnacionais nas diversas áreas da comunicação (Assibercom);

- Aumentar a projeção internacional da comunidade lusófona (Brasil, Portugal, Palop - Países Africanos de Língua Oficial Portuguesa e demais países e comunidades lusófonas) (Lusocom);

- Estabelecer articulações com associações congêneres de áreas conexas, representando o espaço ibero-americano nas confederações mundiais das áreas de humanidades ou de ciências sociais aplicadas (Confibercom).

É interessante notar que todas as organizações citadas, exceto a mais recente, Confibercom (de 2009), foram criadas no mesmo ano: 1998. Nesta altura, em comemoração aos seus 20 anos, é provável que tais associações estejam a realizar um balanço de suas contribuições e avanços para o campo das ciências da comunicação. 
Em termos de avanços, é certo que os eventos científicos organizados por tais órgãos e suas publicações coletivas são fundamentais para o campo, especialmente se considerarmos que grande parte desse volume de conhecimento produzido está disponível para consulta nas bibliotecas on-line. No entanto, embora exista tal democratização do conhecimento, observa-se ainda

uma crescente fragmentação e distribuição desigual de recursos no que toca ao ensino, à aprendizagem e à crítica cultural. Esta dicotomia é válida a diversos níveis - ao nível local e regional, ao nível nacional e entre países, mas também entre regiões e continentes - o que significa que nem todos os cientistas sociais têm acesso aos mesmos recursos e aparatos científicos e metodológicos. (Cunha, 2013: 153)

São entraves ainda não solucionados que acabam por impactar negativamente a realização de projetos coletivos internacionais e a consequente possibilidade de utilização de bibliografia latino-americana partilhada, e reforçam a ideia que "a existência de um espaço institucional comum não necessariamente se relaciona à existência de um espaço cognitivo compartilhado, nem de uma agenda coletiva de investigação" (Romancini, 2017: 4).

Por outro lado, as dificuldades para realização de pesquisas científicas, coletivas ou não, se intensificam na medida em que não somos falantes nativos da atual língua franca, não dominamos os corpos editoriais das principais revistas anglo-saxônicas e, talvez consequência destes dois últimos pontos, publicamos artigos de forma esparsa nos periódicos indexados às principais bases de dados que dominam o mercado editorial global (Cunha, 2013; Serra, 2016).

Assim, o campo da pesquisa em comunicação nos países de língua portuguesa e castelhana tenta o difícil equilíbrio entre acompanhar os rigorosos processos de globalização do conhecimento, seguindo os padrões impostos pelo mercado científico anglo-saxão, na tentativa de internacionalização do conhecimento produzido pelo Sul e, ao mesmo tempo, unir de forças entre os países que partilham a mesma língua e, em grande medida, possuem um repertório comum de memórias históricas e culturais. Particularmente em Portugal parece ocorrer o mesmo fenômeno - os investigadores se dividem entre se voltar para a Europa ou para os países que compõem a Comunidade dos Países de Língua Portuguesa (CPLP). A problematização do segundo ponto, relacionado ao primeiro, nos interessa particularmente. Quais ações têm sido realizadas para fomentar o diálogo entre a produção científica lusófona e ibero-americana com intuito de ampliar o impacto geral destes países face ao Norte dominante? 


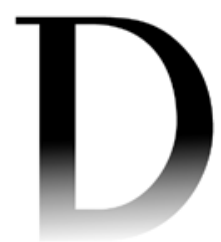

\section{MARTÍN-BARBERO NOS TEXTOS DOS EVENTOS LUSÓFONOS E LATINO-AMERICANOS}

Ao observar as citações presentes nos artigos publicados nas atas/anais desses congressos, notamos que ainda persiste a ausência de diálogo entre os países que formam a comunidade científica lusófona e ibero-americana. Serra (2016) confirma tal fenômeno ao avaliar o grau de conhecimento/desconhecimento mútuo dos investigadores a partir da análise de revistas de ciências da comunicação em três países (Portugal, Brasil e Espanha). Os resultados de sua pesquisa indicam duas tendências: autores costumam citar autores do mesmo país e língua, ou seja, há pouco cruzamento entre países; predominam as citações de autores anglo-saxões. Mesmo quando há uma proximidade gerada pelo desenvolvimento de projetos comuns, por exemplo, na área da ficção televisiva (Cunha, Castilho; Guedes, 2017) e da comunicação e política (Cunha, 2017b), observamos que o maior número de autores comuns citados por ambas as nacionalidades é de língua inglesa ou francesa, embora surjam autores das duas nacionalidades participantes nos textos produzidos.

No mesmo sentido, Cicilia Peruzzo contata que a produção científica dos periódicos da área está dispersa (também incluindo as questões de financiamento, bases de dados e circulação internacional), há pouco consumo dos textos de revistas científicas e "a maior busca de literatura parece ser ainda a estrangeira, principalmente de autoria de norte-americanos e europeus, a exemplo dos papers apresentados em congressos. Alguém disse num dos fóruns: 'Cada vez produzimos mais, mas nos citamos menos..." (2017: 221).

Na primeira fase de análise de atas/anais de congressos organizados pelas associações supracitadas, observamos a presença/ausência de autores a partir de uma lista de fundadores do pensamento latino-americano, entre eles

${ }^{5} \mathrm{O}$ discurso de abertura do congresso da IAMCR, "Bastard mutations of communication", está disponível para consulta em: <https://goo.gl/6HxqZi> (acesso em: 20 mar. 2018), e também publicado nesta edição de MATRIZes. Martín-Barbero, mencionada por Omar Rincón ${ }^{5}$ na conferência de abertura do congresso da International Association for Media and Communication Research (IAMCR), realizada em Cartagena das Îndias, Colômbia, em 2017.

Além de confirmar as tendências anteriores, na Tabela 1 é possível identificar o espaço ocupado pelos autores latino-americanos nos quase dois mil trabalhos publicados nas atas/anais dos eventos lusófonos e ibero-americanos dos últimos 15 anos. Jesús Martín-Barbero e Néstor García Canclini são os autores mais citados, sobressaindo-se o primeiro, conforme o esperado. De qualquer forma, os 212 artigos que referem pelo menos uma vez Martín-Barbero representam cerca de 10\% desta amostra (Tabela 1), evidenciando relativa ausência dos fundadores do pensamento latino-americano no conhecimento científico produzido por seus concidadãos no panorama atual. Percebe-se que essa tendência é mais acentuada nos congressos realizados 
pela Sopcom e Lusocom, ou seja, eventos sediados, em sua maioria, em Portugal. O mesmo ocorre nos textos publicados no Anuário Internacional da Comunicação Lusófona.

\begin{tabular}{|c|c|c|c|c|c|c|}
\hline $\begin{array}{c}\text { Autores } \\
\text { latino-americanos }\end{array}$ & Ibercom & Con5ber-com & $\begin{array}{l}\text { Lusocom } \\
\text { (Anuário) }\end{array}$ & $\begin{array}{l}\text { Lusocom } \\
\text { (Atas) }\end{array}$ & Sopcom & Total \\
\hline Jesus Martín-Barbero & 112 & 32 & 10 & 29 & 29 & 212 \\
\hline Néstor García Canclini & $5 S$ & 21 & 9 & 20 & 14 & 122 \\
\hline Paulo Freire & 35 & 11 & 4 & 19 & 9 & $7 S$ \\
\hline $\begin{array}{l}\text { Maria Immacolata } \\
\text { Vassallo de Lopes }\end{array}$ & 44 & 11 & 6 & 6 & 10 & 77 \\
\hline Guillermo Orozco & 24 & 5 & 4 & 3 & 6 & 42 \\
\hline Arlindo Machado & 14 & 4 & 2 & - & 7 & 27 \\
\hline $\begin{array}{c}\text { Ismar de Oliveira } \\
\text { Soares }\end{array}$ & 11 & 7 & - & 4 & 3 & 25 \\
\hline Renato Ortiz & 4 & 4 & 5 & 6 & 4 & 23 \\
\hline Eliseo Verón & 9 & 5 & - & - & 4 & $1 S$ \\
\hline Mario Kaplún & S & 5 & - & 1 & 2 & 16 \\
\hline Luis Ramiro Beltrán & 4 & - & 2 & 3 & 3 & 12 \\
\hline Rossana Reguillo & 7 & 1 & - & - & 1 & 9 \\
\hline Valerio Fuenzalida & 2 & 2 & 1 & 2 & - & 7 \\
\hline Rosa María Alfaro & 3 & 1 & - & 2 & - & 6 \\
\hline Aníbal Ford & - & - & - & 1 & 2 & 3 \\
\hline Antonio Pasquali & - & - & 1 & 1 & - & 2 \\
\hline María Cristina Mata & 2 & - & - & - & - & 2 \\
\hline Carlos Monsiváis & - & 1 & - & 1 & - & 2 \\
\hline
\end{tabular}

TABELA 1 - Número de artigos que citam os fundadores do pensamento latino-americano

Fonte: Dados e elaboração das autoras

Ao analisar a nacionalidade dos autores dos artigos que utilizaram Martín-Barbero como uma de suas referências (Tabela 2), percebemos uma quantidade muito superior (182) de brasileiros que o citam em todos os congressos observados, com destaque para sua presença nos artigos do Ibercom. Os portugueses realizaram apenas seis artigos com menção a este teórico, o que representa $0,3 \%$ da amostra. Assim, ao contrário dos portugueses, os brasileiros estão mais próximos do pensamento latino-americano nos textos analisados.

Além disso, embora haja um fluxo crescente de brasileiros a realizar ensino superior e formação pós-graduada em Portugal (Oliveira et al., 2015), não há citações de autores brasileiros e de Martín-Barbero em artigos de autores 
brasileiros matriculados em instituições portuguesas. Acresce-se que não há dados sobre o número de estudantes de pós-graduação portugueses em universidades brasileiras e latino-americanas. Esta constatação aponta, por um lado, para a necessidade de aprofundar o intercâmbio de estudantes e docentes no espaço latino-americano (Oliveira; Baldi, 2017), por outro lado, indicia que o movimento de atração de pesquisadores se dá preferencialmente em direção à Ibéria, onde o acesso à pesquisa e ao repertório científico dominante, leia-se anglo-saxônico, fica mais próximo.

\begin{tabular}{|c|c|c|c|c|c|c|}
\hline $\begin{array}{c}\text { Nacionalidade dos } \\
\text { autores dos artigos }\end{array}$ & Ibercom & Con5ber-com & $\begin{array}{c}\text { Lusocom } \\
\text { (Anuário) }\end{array}$ & $\begin{array}{c}\text { Lusocom } \\
\text { (Atas) }\end{array}$ & Sopcom & Total \\
\hline $\begin{array}{c}\text { Brasileiros de } \\
\text { instituição brasileira }\end{array}$ & 94 & 29 & 9 & $2 S$ & 20 & 1 S2 \\
\hline $\begin{array}{c}\text { Brasileiros de } \\
\text { instituição portuguesa }\end{array}$ & - & - & - & - & - & - \\
\hline $\begin{array}{c}\text { Brasileiros de } \\
\text { outras instituições } \\
\text { CPLP/ibero-americanas }\end{array}$ & 1 & - & - & 1 & - & 2 \\
\hline $\begin{array}{c}\text { Portugueses de } \\
\text { instituição portuguesa }\end{array}$ & 2 & 1 & - & - & 3 & 6 \\
\hline $\begin{array}{c}\text { Portugueses de } \\
\text { instituição brasileira }\end{array}$ & - & - & - & - & - & - \\
\hline $\begin{array}{c}\text { Outros países } \\
\text { ibero-americanos }\end{array}$ & 15 & 2 & 1 & - & 6 & 24 \\
\hline $\begin{array}{c}\text { Outros países } \\
\text { Total }\end{array}$ & - & - & - & - & - & - \\
\hline
\end{tabular}

TABELA 2 - Nacionalidade dos autores nos artigos que citam Martín-Barbero Fonte: Dados e elaboração das autoras

\section{AUSÊNCIAS E PRESENÇAS DE MARTÍN-BARBERO EM PORTUGAL}

Uma das razões apontadas nas entrevistas para a ausência de referências a Martín-Barbero nos textos dos investigadores portugueses é o desconhecimento dos estudos latino-americanos de comunicação. Este desconhecimento repercute nas bibliografias oficiais dos programas das disciplinas ministradas nas instituições de ensino superior em Portugal, onde são raras as menções a autores brasileiros e latino-americanos. Além do desconhecimento de estudos e pesquisadores brasileiros e latino-americanos, assinalamos a dificuldade de aceder fisicamente às obras clássicas com esta procedência a que se junta uma certa retração dos alunos portugueses, face à leitura de obras em português do Brasil e língua espanhola. A estes elementos, verificados empiricamente, somamos as diretivas de avaliação aos cursos de pós-graduação que privilegiam a 
internacionalização da bibliografia utilizada, entendendo-se que esta passa pela referenciação de reportórios bibliográficos anglo-saxônicos. Salientamos que a permanência e a realização de teses de mestrado e doutoramento de alunos brasileiros em Portugal têm permitido o cruzamento de bibliografias e autores por estes alunos, dado que, para verem reconhecidos os graus de pós-graduação nas instituições brasileiras, necessitam de incluir em seus trabalhos acadêmicos referências que possam ser identificadas pelos júris daquelas instituições.

Por exemplo, as opiniões de docentes e pesquisadores, como Cláudia Álvares ${ }^{6}$, Paulo Serra ${ }^{7}$ e Rita Figueiras ${ }^{8}$, são esclarecedoras ao reconhecerem que desconhecem investigadores portugueses cujo trabalho foi, de alguma forma, influenciado pela obra de Jesús Martín-Barbero, particularmente De los medios a las mediaciones. São casos isolados os que utilizam MartínBarbero como referência, como no livro de Manuel Pinto e colaboradores (2011), sobre educação para os meios em Portugal, no qual a importância das mediações sociais apontada por Martín-Barbero 9 é uma ideia utilizada para contrapor a visão instrumentalista das tecnologias da informação e da comunicação (TIC).

De maneira geral, Serra considera que a influência de Martín-Barbero foi mínima ou nula na afirmação e desenvolvimento do campo das pesquisas em ciências da comunicação em Portugal. Segundo ele, embora os "fundadores do campo" ${ }^{10}$ (Serra, 2017), possam ter lido e discutido a obra de Martín-Barbero, nenhum deles denota influência deste autor em suas linhas de investigação.

Outro ponto destacado diz respeito ao fato do campo das ciências da comunicação em Portugal ter sido formado com base numa tradição francesa e, mais recentemente, anglo-saxônica, em que o pensamento de Martín-Barbero possui menor expressividade ${ }^{11}$. Por vezes o diálogo entre o pensamento de Martín-Barbero e essas matrizes teóricas é visto como inadequado, conforme ilustra Cláudia Álvares. Apesar de ter utilizado Martín-Barbero como uma de suas referências bibliográficas, em texto enviado para uma revista científica, Álvares retirou a referência $a$ posteriori com base na argumentação dos pareceristas: Martín-Barbero não se encaixava de modo fluido no texto, pois seu pensamento divergia da "linha orientadora" principal do trabalho.

É nesse sentido que Ciro Marcondes Filho indica que certos impasses teóricos não foram devidamente problematizados por Jesús Martín-Barbero, Néstor García Canclini e Guilhermo Orozco Gómez, principais expoentes dos estudos latino-americanos de comunicação.

A teoria da comunicação latino-americana é uma ilha solitária, que busca com seus próprios - e muitas vezes escassos - recursos teóricos dar conta da complexidade de
${ }^{6}$ Presidente da European Communication Research and Education Association (ECREA) entre 2012-2016 e docente da Universidade Lusófona de Humanidades e Tecnologias.

${ }^{7}$ Presidente da Sopcom e da Faculdade de Artes e Letras da Universidade Beira Interior (Portugal).

${ }^{8}$ Docente da Faculdade de Ciências Humanas da Universidade Católica Portuguesa (UCP), na área da comunicação. Desenvolve trabalhos cuja linha de pesquisa dialoga com MartínBarbero (Figueiras, 2017).

${ }^{9}$ Martín-Barbero (2002).

${ }^{10}$ Nomeadamente: Adriano Duarte Rodrigues, Aníbal Alves, Moisés de Lemos Martins, José Paquete de Oliveira e António Fidalgo.

${ }^{11}$ Também conforme dados do estudo bibliométrico realizado por Abadal e Vidal (2017: 50). 
um processo comunicacional em tempos de mudanças vertiginosas [...]. Talvez por isso encontre poucos ecos nos Estados Unidos e na Europa. (Marcondes Filho, 2008: 69)

Outra questão assinalada diz respeito aos contornos ideológicos tomados pelos estudos latino-americanos, segundo Marcondes, de caráter indissociavelmente político, perfeitamente adequados aos que acreditam na comunicação como instrumento de mudança social e política por meio da cultura. Esta observação aponta para uma discussão mais profunda sobre o paradigma da ciência dominante de cunho ocidental, colonial e patriarcal (Grosfoguel, 2013), e um outro paradigma centrado na possibilidade de uma abordagem científica pós-colonial, onde o pensamento de Martín-Barbero se insere de forma disruptiva e autônoma face aos modelos estabelecidos pelo Norte.

De fato, a proposta de Martín-Barbero é uma perspectiva centrada na análise dos fenômenos da comunicação a partir do trinômio comunicação-cultura-política (Lopes, 2014). Martín-Barbero pensou as mediações como um "lugar' de onde é possível compreender a interação entre o espaço da produção e o da recepção” (Martín-Barbero apud Lopes, 2014: 68), por isso:

Esta contribuição pode ser vista como uma tentativa de ultrapassar abordagens teóricas fragmentadas e simplificadas posicionando as mediações como uma perspectiva teórica integrada da produção, produto e audiência dentro dos estudos comunicacionais. A comunicação passa, então, a ser vista como um domínio privilegiado para a produção de sentido da vida. (Lopes, 2014: 66)

A contribuição da perspectiva teórica das mediações de Martín-Barbero se tornou fundamental para os estudos latino-americanos de recepção (Ibid.). No Brasil, podemos mesmo dizer que a tradição dos estudos de recepção está ancorada no pensamento de Martín-Barbero: "Hoje a perspectiva teórica das mediações e da hibridização tem uma presença central na pesquisa de recepção na América Latina" (Ibid.: 67).

É por meio dos estudos de recepção, especialmente da telenovela, que o pensamento de Martín-Barbero surge nas investigações em Portugal. Isso ocorre de forma esporádica e fundamentalmente em pesquisas realizadas por portugueses que estiveram algum período de estudo no Brasil (e seus respectivos alunos) ou por brasileiros que realizaram estudos em instituições portuguesas.

Neste sentido, colabora o fato dos fluxos do sistema midiático lusófono serem marcados fundamentalmente pela circulação dos conteúdos entre os países, com destaque para a penetração da indústria cultural brasileira, sobretudo a música popular brasileira (MPB) e a ficção televisiva (principalmente telenovelas da 
Rede Globo). Especialmente após a expansão do mercado midiático português, pois "com o final das ditaduras, inicia-se a democratização dos sistemas políticos e o reenquadramento legislativo do sistema mediático" e "O Brasil começou a exportar conteúdos: música e produtos de ficção. Os públicos massificaram-se e tornaram-se mais exigentes" (Cunha, 2017a: 37).

O estudo desses importantes fenômenos midiáticos, culturais e populares, especialmente as problematizações em torno da telenovela (brasileira/portuguesa) nos contextos sociais portugueses, que tomam dimensões analíticas de gênero, classe e outros aspectos do consumo deste produto (Burnay, 2005; Tranquilin, 2007; Castilho, 2010), é realizado com frequência com base nos conceitos de Martín-Barbero. Assim, "a inspiração teórica latino-americana fez-se sentir desde o início dos estudos sobre a telenovela, quer sobre a produção, quer sobre a recepção" (Cunha, 2010: 111).

\section{(IM)POSSIBILIDADES DE DIÁLOGO: DOS FLUXOS MIDIÁTICOS AOS FLUXOS ACADÊMICOS ENTRE BRASIL E PORTUGAL}

Como referimos anteriormente, desde a década de 1950 os fluxos culturais e artísticos entre Portugal e Brasil não cessaram de se intensificar, acompanhando as relações econômicas e políticas, as migrações e o desenvolvimento tecnológico dos meios de comunicação. Independentemente da diferente concepção dos sistemas midiáticos e políticos, o intercâmbio de natureza múltipla e o estreitamento das migrações não pararam de se acentuar entre os dois países. Estes movimentos transatlânticos envolveram, e envolvem, a música popular, as tournées de companhias de teatro, a exibição de humoristas, a edição de livros, as mostras de filmes e documentários, a exposição em galerias de arte de artistas, autores e compositores de ambos os países. A partir dos anos 1970, junta-se a este intercâmbio a publicidade e os produtos televisivos, entre os quais a telenovela da Rede Globo, que adquire grande protagonismo na sociedade portuguesa e no espaço lusófono, por mais de vinte anos.

Em Portugal e no mundo lusófono, a influência da cultura e do linguajar do Brasil, que para muitos intelectuais portugueses significou uma vingança do colonizado frente ao colonizador, originou resistência e o eclodir de preconceitos coloniais, sob diferentes roupagens. A adesão de Portugal à União Europeia (UE) em 1986, e a necessidade de convergência com os países mais ricos e desenvolvidos do grupo, aproximou os pesquisadores portugueses das ciências sociais e humanas, incluindo da comunicação, dos cânones acadêmicos anglo-saxônicos e, simultaneamente afastou-os da maioria dos seus parceiros acadêmicos brasileiros. 
Identificamos três razões objetivas espelhadas nas avaliações periódicas realizadas tanto nos cursos de licenciatura, mestrado e doutoramento, como nos centros de investigação, e ainda nas candidaturas a projetos apoiados pela instituição de apoio à pesquisa em Portugal (Fundação para a Ciência e a Tecnologia, FCT). Nestas avaliações que ditam a qualidade da docência e da investigação da área, os critérios de internacionalização privilegiam: 1) as relações com o norte europeu, considerado mais avançado; 2) o uso de bibliografia internacional (leia-se em língua inglesa) atualizada; e 3 ) as propostas que se enquadrem em metodologias consolidadas em projetos internacionais anteriores.

Neste contexto, as especificidades de países pequenos, como Portugal, deverão integrar-se nos quadros de análise, inquéritos e questionários definidos pelos países do Norte, com o objetivo de tornar comparáveis fenômenos considerados comuns. Embora as agências de pesquisa, docência e avaliação europeias sejam constituídas por membros de todos os países, na verdade há uma hierarquia, a que chamaríamos colonial e linguística, que emerge nessa participação. Talvez por essa razão desponta em muitos pesquisadores portugueses o interesse pelas parcerias com o Brasil, em que muitas vezes se arrogam o estatuto de mediadores entre colegas europeus e brasileiros, replicando uma certa e, muitas vezes inconsciente, relação colonial.

Relembramos, com base nos dados levantados e pelos eventos anteriormente referenciados, a existência de um fluxo intenso de contatos acadêmicos, científicos e interpessoais entre Portugal e o Brasil e, com menos intensidade, embora frequentes, entre Portugal, Espanha e o conjunto dos países da América Latina. No entanto, essa convivência não implicou, até o momento, uma partilha de conhecimentos na área científica e muito menos o reconhecimento mútuo de pesquisadores.

Como compreender e justificar uma relação estreita de fluxos acadêmicos, ao nível pessoal, e uma desconexão quase absoluta ao nível da interpenetração da pesquisa? Tentaremos em seguida avançar com algumas explicações que necessariamente deverão ter em conta o mundo globalizado e o clima econômico e político em que o fazer da ciência se insere.

Nos últimos anos, a controvérsia em torno das formas de fazer pesquisa em ciências sociais e, por conseguinte nos estudos sobre mídia e comunicação, tem vindo a crescer. A discussão sobre a forma de fazer pesquisa em ciências sociais tem envolvido, prioritariamente, a contestação à cristalização de roteiros e à utilização de procedimentos consolidados, que tendem a refletir a geoeconomia da globalização hegemônica. As críticas incidem em numerosos aspectos, tais como a hierarquização de objetos pesquisados, a valorização de cânones e formatos de pesquisa em detrimento dos conteúdos da descoberta, a 
estrutura de citações mobilizada, nomeadamente de autores consensualizados pela pesquisa anglo-saxônica, com vista a suportar afirmações e constatações. As críticas ressaltam, igualmente, a primazia da forma sobre o conteúdo, da autoridade das citações sobre a originalidade do pensamento, da reprodução sobre a inovação.

Esta crítica advém da tendência de cristalização e hierarquização teórica e metodológica, em que parece estar patente uma escala interiorizada de abordagens e de legitimação que dependem diretamente de fatores como a proveniência geográfica e linguística dos autores, assim como dos acessos disponibilizados. Este procedimento generalizou-se e está hoje presente nas ciências sociais em geral, mas também nos estudos de mídia e comunicação, em que prevalecem a hierarquização e a legitimação da pesquisa em função não dos resultados alcançados, mas sobretudo da obediência a desenhos e formatos de pesquisa consolidados, assim como a filiações teóricas e metodológicas consagradas.

Como nota Janine Ribeiro (2003: 146), há uma tendência para criação de franchisings de autores renomados nos países do Sul, numa clara relação de subalternidade, pois o pesquisador nacional geralmente não assume tal posição de destaque no exterior, porém tal prática segue valorizada no meio acadêmico no Brasil, assim como acontece em Portugal.

Neste ecossistema de pesquisa temos assistido à emergência de um star system de autoridades em áreas temáticas, replicando os estrelatos midiáticos e as estratégias de midiatização identificadas em outras áreas, como a política ou a justiça. Tal como em outras atividades sociais e particularmente nas indústrias culturais, este fenômeno emergiu entre pares, a nível nacional, mas também entre pares ao nível regional e global. Não é um fenômeno necessariamente linear, na medida em que se reconhecem estrelas/autoridades nacionais incapazes de aceder ao palco internacional, e por sua vez estrelas/ autoridades internacionais que não são reconhecidas dentro da sua área nacional de atuação. O que é comum às estrelas/autoridades que compõem o star system da pesquisa é a capacidade de impor, manter e perpetuar, a partir de escolas e centros de pesquisa nacionais ou internacionais, o predomínio de determinados paradigmas, confirmando velhas observações realizadas por Thomas Kuhn (1998) nos anos 1960 sobre a estrutura das revoluções científicas. Caracteriza, igualmente, este pequeno grupo, o poder que detém e os acessos que controlam em universidades, centros de financiamento à pesquisa, centros de pesquisa, editoras, organizações profissionais, redações de meios de comunicação, etc. De certa forma, reproduz-se no mundo da ciência e da pesquisa os parâmetros dominantes na sociedade globalizada, na forma como se processa a distribuição de poder, nas áreas de influência 
e também nos acessos aos meios de comunicação, neste caso revistas e sites especializados - de preferência de editoras anglo-saxônicas - e fóruns nacionais e internacionais (associações, congressos, conferências, etc.).

\section{CONSIDERAÇÕES FINAIS}

Embora Martín-Barbero seja o pensador latino-americano mais lido e citado (ou um dos) no campo da comunicação no Brasil, em Portugal configura-se como uma referência praticamente ignorada pela maior parte dos intelectuais e pelos programas de pós-graduação nesta área.

Esta ausência de Martín-Barbero em Portugal deve ser entendida dentro dos contextos apresentados (heranças do pensamento colonialista e posicionamentos pós-colonialistas, aproximação à União Europeia, valorização da matriz anglo-saxônica, configurando-se uma anglo-internacionalização), e não é espectável que, pela mesma razão, haja maior interpenetração em Portugal de autores latino-americanos, embora o contrário - isto é, autores portugueses e europeus no Brasil - seja, à luz desta globalização da ciência, mais plausível. Não é por acaso que as obras de pesquisadores portugueses que traduziram, comentaram ou reorganizaram textos de origem anglo-saxônica ou francesa estejam entre os mais citados no Brasil.

Este processo contrapõe-se e acompanha a massificação do ensino superior e da pesquisa exigida a estudantes, professores e investigadores do ensino superior, tanto em Portugal como no Brasil. A massificação da pesquisa, principalmente nas ciências sociais, democratiza na base o acesso a conhecimentos fundamentais sobre as dinâmicas sociais, cria uma massa crítica capaz de colocar em causa o status quo de uma determinada sociedade. É essa democratização que torna possível a emergência de múltiplas correntes de pensamento que, naturalmente, concorrem, cooperam, comparam e mutuamente tendem a excluir-se. Fazer ciência tornou-se um imperativo no ensino superior, nomeadamente nas ciências sociais, mas as condições de produção da ciência são cada vez mais diferenciadas, em função dos espaços geográficos (em que continente, país, cidade, bairro os pesquisadores se situam), linguísticos (por exemplo, português, espanhol ou inglês), socioeconômicos e políticos. Fazer ciência em ciências sociais é assim um empreendimento, à partida, altamente condicionado pelas circunstâncias exteriores à atividade científica.

A deriva neoliberal da globalização acrescentou, na última década, novos elementos à dinâmica do conhecimento e da pesquisa em ciências sociais, tais como os rankings de avaliação das instituições de ensino e de pesquisa, dos programas de pós-graduação e da atividade dos docentes e pesquisadores, 
assentes em critérios de mensuração de produção decalcados nas ciências exatas, da saúde, biomédicas, etc., com vista a aferir a produtividade e, por conseguinte, a aplicabilidade produtiva da atividade científica. À luz desta conjuntura, as ciências sociais - independentemente de contabilizarem uma imensa produção e de alimentarem milhares de revistas (em papel e on-line), sites, coleções de livros, atas de congressos, etc., mobilizarem milhares, ou milhões, de docentes, pesquisadores e alunos - comportam-se mal. As ciências sociais não são produtivas no sentido definido, e em fase de consolidação, pelas políticas públicas do capitalismo neoliberal, apesar de movimentarem uma apreciável atividade econômica, como o ensino e a editoração. Contudo, os resultados das pesquisas, na generalidade, não resultam em aumentos imediatos de produção, não levam a patentes ou à imediata aplicabilidade na inovação de produtos ou no aumento de exportações. Pelo contrário, as ciências sociais tendem a criar uma imensa massa crítica, capaz de colocar em questão as mesmas políticas públicas, contribuindo para a desclassificação da agenda produtiva neoliberal.

Os estudos de mídia e comunicação que se inserem no guarda-chuva das ciências sociais são das poucas áreas com potencial para incidirem diretamente sobre a atividade produtiva e alterarem, a partir do terreno, comportamentos e habitus de empresas, instituições e pessoas.

Por enquanto, os estudos de mídia e comunicação em Portugal continuam a replicar as condutas de sua área regional mais ampla ao inaugurar e perpetuar filiais de estudos do Norte de forma a adular as celebridades acadêmicas do nosso tempo. Neste contexto, há pouco a esperar em termos de contribuição para avanços críticos no campo, tendo em vista que tais autoridades desconhecem os problemas locais e as particularidades de países que possuem raízes culturais e históricas mais próximas de outros contextos, como o latino-americano. $\mathbf{M}$

\section{REFERÊNCIAS}

ABADAL, E.; VIDAL, G. Análisis bibliométrico: citas, ediciones, traducciones. In: MORAGAS, M.; TERRÓN, J. L.; RINCÒN, O. (Eds.). De los medios a las mediaciones de Jesús Martín-Barbero, 30 años después. Barcelona: InCom-UAB, 2018. p. 50-63. Disponível em: <https://goo.gl/EPGqXi>. Acesso em: 20 mar. 2018.

BOURDIEU, P. O campo científico. In: ORTIZ, R. (Org.). Pierre Bourdieu. São Paulo: Ática, 1983. p. 122-155.

BURNAY, C. D. A telenovela e o público: uma relação escondida. Media \& Jornalismo, Coimbra, n. 6, p. 95-110, 2005. 
CASTILHO, F. Telenovela e recepção: um estudo com famílias da "classe trabalhadora" portuguesa. 2010. 170 f. (Mestrado em Comunicação e Jornalismo) Universidade de Coimbra, Coimbra, 2010.

CUNHA, I. F. Audiências e recepção das telenovelas brasileiras em Portugal. Comunicação, Mídia e Consumo, São Paulo, v. 7, n. 20, p. 91-118, nov. 2010. . Memórias da telenovela: programas e recepção. Lisboa: Horizonte, 2011. - A globalização da investigação em ciências sociais: o caso dos estudos de comunicação no espaço ibero-americano e lusófono. MATRIZes, São Paulo, v. 7, n. 1, p. 149-165, jan./jun. 2013. DOI: http://dx.doi.org/10.11606/ issn.1982-8160.v7ilp149-165

. (Des)continuidades: o sistema mediático lusófono. In: CUNHA, I. F.; CASTILHO, F.; GUEDES, A. P. (Orgs.). Ficção seriada televisiva no espaço lusófono. Covilhã: LabCom.IFP, 2017a. p. 15-42. Disponível em: <https:// goo.gl/KpTDqC >. Acesso em: 20 fev. 2018.

. Pesquisa cooperativa e comparativa: o projeto "Média e corrupção (Portugal, Brasil e Moçambique)". In: GAMA, M.; SOUSA, H. (Eds.). Redes de cooperação cultural transnacionais: um olhar sobre a realidade lusófona. Braga: Cesc, 2017b. p. 24-46. Disponível em: <https://goo.gl/XQuUbQ>. Acesso em: 20 fev. 2018.

CUNHA, I. F.; CABRERA, A.; SOUSA, J. P. (Orgs.). Pesquisa em media e jornalismo: homenagem a Nelson Traquina. Covilhã: LabCom.IFP, 2012. Disponível em: <https://goo.gl/h9rM8H>. Acesso em: 20 fev. 2018.

CUNHA, I. F.; CASTILHO, F.; GUEDES, A. (Orgs.). Ficção seriada televisiva no espaço lusófona. Covilhã: LabCom.IFP, 2017. Disponível em: $<$ https://goo.gl/KpTDqC >. Acesso em: 20 fev. 2018.

FIGUEIRAS, R. Estudos em mediatização: causalidades, centralidades, interdisciplinaridades. MATRIZes, São Paulo, v. 11, n. 1, p. 101-126, jan./abr. 2017. DOI: http://dx.doi.org/10.11606/issn.1982-8160.v11ilp101-126

GONÇALVES, J. J. Política de informação: ensaios. Lisboa: Junta de Investigações do Ultramar; Cesp, 1963.

GROSFOGUEL, R. Desenvolvimentismo, modernidade e teoria da dependência na América Latina. Revista de Estudos AntiUtilitaristas e PosColoniais, Recife, v. 3, n. 2, p. 26-55, 2013.

JANINE RIBEIRO, R. A universidade e a vida atual: Fellini não via filmes. Rio de Janeiro: Campus, 2003.

KUHN, T. A estrutura das revoluções científicas. 5. ed. São Paulo: Perspectiva, 1998.

LOPES, M. I. V. Mediação e recepção: algumas conexões teóricas e metodológicas nos estudos latino-americanos de comunicação. MATRIZes, São Paulo, v. 8, n. 1, p. 65-80, jan./jun. 2014. DOI: http://dx.doi.org/10.11606/ issn.1982-8160.v8i1p65-80 
MARCONDES FILHO, C. Martin-Barbero, Canclini, Orozco: os impasses de uma teoria da comunicação latino-americana. Famecos, Porto Alegre, v. 35, n. 1, p. 69-85, 2008. DOI: http://dx.doi.org/10.15448/1980-3729.2008.35.4095

MARCOS, L. H.; MORENO, C. Memória e comunicação no contexto ibero-americano: entrevista a Carlos Alexandre de Carvalho Moreno. Intercom, São Paulo, v. 26, n. 1, p. 91-101, jan./jun. 2003.

MARTÍN-BARBERO, J. A que se puede llamar hoy televisión pública? Telos, Madri, n. 51, abr./jun. 2002. Disponível em: <https://goo.gl/TeTFW9>. Acesso em: 20 mar. 2018.

MELO, J. M. Associações nacionais e internacionais criam confederação ibero-americana para fortalecer as ciências da comunicação. Intercom, São Paulo, v. 32, n. 2, p. 265-268, jul./dez. 2009.

MESQUITA, M.; PONTE, C. Situação do ensino e da formação profissional na área do jornalismo. Covilhã: Bocc Portugal, 1997. Relatório de pesquisa.

OLIVEIRA, L.; BALDI, V. O potencial educativo do território hipermediatizado: dos lugares do conhecimento ao conhecimento coproduzido nos lugares. Prisma.com, Porto, n. 28, p. 65-85, 2017.

OLIVEIRA, I. et al. Estudantes estrangeiros em Portugal: evolução e dinâmicas diferentes (2005-2013). Revista de Estudos Demográficos, Lisboa, v. 54, p. 39-56, 2015. Disponível em: <https://goo.gl/ftfCDM>. Acesso em: 20 fev. 2018.

PERUZZO, C. M. K. Diagnóstico e perspectivas dos periódicos científicos e difusão do conhecimento comunicacional nos primeiros anos da Confibercom (2011-2015). In: MARTINS, M. L. (Org.). A internacionalização das comunidades lusófonas e ibero-americanas de ciências sociais e humanas: o caso das ciências da comunicação. Ribeirão: Cecs, 2017. p. 217-230. Disponível em: <https://goo.gl/xPz6tK>. Acesso em: 20 fev. 2018.

PINTO, M. et al. Educação para os media em Portugal: experiências, actores e contextos. Lisboa: ERC, 2011.

REGO, A. S. et al. Curso de jornalismo. Lisboa: Junta de Investigações do Ultramar; Cesp, n. 60, 1963.

RIBEIRO, N. Communication studies on the Iberian Peninsula: a comparative analysis of the field's development in Portugal and Spain. In: SIMONSON, P.; PARK, D. W. (Eds.). The international history of communication study. Londres: Routledge, 2016. p. 151-170.

ROMANCINI, R. Visibilidade mundial e referências comuns nos estudos de comunicação e educação no espaço ibero-americano. In: CONGRESSO BRASILEIRO DE CIÊNCIAS DA COMUNICAÇÃO, 40., 2017, Curitiba. Anais... Curitiba: Intercom, 2017. p. 1-13. 


\section{A ausência de Jesús Martín-Barbero nos estudos de comunicação em Portugal}

SARAMAGO, J. A jangada de pedra. Lisboa: Caminho, 1986.

SERRA, P. O (des)conhecimento recíproco dos investigadores ibero-americanos de ciências da comunicação. Revista Lusófona de Estudos Culturais, Lisboa, v. 3, n. 2, p. 57-68, 2016.

. Disciplinas, paradigmas e olhares: o lugar de Paquete de Oliveira na construção do campo das ciências da comunicação em Portugal. Comunicando, Lisboa, v. 6, n. 1, p. 132-143, 2017.

TRANQUILIN, J. O erótico em Senhora do destino: recepção de telenovela em Vila Pouca do Campo, Portugal. 2007. 351 f. (Doutorado em Ciências Sociais) - Pontifícia Universidade Católica de São Paulo, São Paulo, 2007.

Artigo recebido em 30 de agosto de 2017 e aprovado em 12 de dezembro de 2017. 